\title{
Removal of Tannic Acid Stabilizes CuO Nanoparticles from Aqueous Media by PAFC: Effect of Process Conditions and Water Chemistry
}

\author{
Rizwan Khan ${ }^{1}\left(\mathbb{D}\right.$, Muhammad Ali Inam ${ }^{2} \mathbb{D}$ and Kang Hoon Lee ${ }^{3, *}$ \\ 1 Department of Chemical Engineering, Quaid-e-Awam University of Engineering, \\ Science and Technology (QUEST), Nawabshah 67480, Pakistan; rizwansoomro@quest.edu.pk \\ 2 Institute of Environmental Sciences and Engineering (IESE), School of Civil and Environmental \\ Engineering (SCEE), National University of Sciences and Technology (NUST) H-12 Campus, \\ Islamabad 44000, Pakistan; ainam@iese.nust.edu.pk \\ 3 Department of Civil and Environmental Engineering, Hanyang University, 222 Seongdong-gu, \\ Seoul 04763, Korea \\ * Correspondence: diasyong@hanyang.ac.kr
}

Citation: Khan, R.; Inam, M.A.; Lee, K.H. Removal of Tannic Acid Stabilizes CuO Nanoparticles from Aqueous Media by PAFC: Effect of Process Conditions and Water Chemistry. Molecules 2021, 26, 5615. https://doi.org/10.3390/ molecules 26185615

Academic Editors: Carlo Santoro

Received: 26 July 2021

Accepted: 14 September 2021

Published: 16 September 2021

Publisher's Note: MDPI stays neutral with regard to jurisdictional claims in published maps and institutional affiliations.

Copyright: (c) 2021 by the authors. Licensee MDPI, Basel, Switzerland. This article is an open access article distributed under the terms and conditions of the Creative Commons Attribution (CC BY) license (https:// creativecommons.org/licenses/by/ $4.0 /)$.

\begin{abstract}
The increased utilization of $\mathrm{CuO}$ nanoparticles ( $\mathrm{CuO}$ NPs) in various fields has raised concerns about their discharge into water containing a wide range of organic ligands. Moreover, the adsorption of these ligands can stabilize the $\mathrm{CuO}$ NPs in drinking water treatment plants. Thus, their removal from potable water is important to mitigate the risk to humans. The present study explored the efficacy of the coagulation-sedimentation $(\mathrm{C} / \mathrm{S})$ process for the removal of tannic acid (TA)-stabilized $\mathrm{CuO}$ NPs using polyaluminum ferric chloride (PAFC) as a coagulant. Moreover, the influence of process conditions (stirring speed) and water chemistry (i.e., $\mathrm{pH}$ and ionic strength (IS)) were also investigated to determine their impact on removal. The results showed that stirring speed in the reaction phase significantly affected the removal due to increased flocculation compared with stirring speed in the mixing phase. In addition, $\mathrm{pH}$ and IS affect the colloidal stability and removal efficiency of $\mathrm{CuO}$ NPs. A relatively better removal performance $(<99 \%)$ of $\mathrm{CuO}$ NPs was found at lower coagulant dosage in the $\mathrm{pH}$ range 6-8. The addition of organic ligands reversed the surface charge potential and enhanced the colloidal stability of $\mathrm{CuO}$ NPs, resulting in the destabilization of TA-CuO NPs, thereby reducing the optimum PAFC dosage for removal. By contrast, the IS above the critical coagulation concentration decreased the removal efficiency due to inhibition of the ionic activity of PAFC hydrolysate in the aqueous environment. Fourier transform infrared findings of TA-CuO NPs composite flocs suggest that the primary removal mechanism might be mediated via the combined effect of neutralization, complexation as well as adsorption.
\end{abstract}

Keywords: organic ligands; tannic acid; coagulation; sedimentation; nanoparticles; polyaluminum ferric chloride

\section{Introduction}

Copper oxide nanoparticles (CuO NPs) are detected in aqueous environments due to their enhanced production and usage [1-3]. The organic ligands adsorb onto the surface of $\mathrm{CuO}$ NPs, thereby increasing their fate and transportation in water [4,5]. Moreover, the ligand-stabilized NPs may find their way into the human body via drinking water treatment plants. Many previous studies reported the hazardous effects of CuO NPs on aquatic species and humans [2,6]. Therefore, it is essential to effectively remove the organic ligand-stabilized $\mathrm{CuO}$ NPs from the potable water treatment plants.

The transportation of NPs in the water can be limited by many processes, i.e., bioremediation, ion exchange, membrane separation, adsorption, coagulation and sedimentation. A few studies reported that metal-based NPs can be controlled via biosorption-activated sludge techniques; however, the removal by bacterial film is significantly affected by the 
toxicity of nanoparticles [7,8]. The removal of NPs can be achieved via filtration; however, blockage of membrane pores due to NPs increases the treatment cost [9]. Earlier studies confirmed the removal of different metal oxides, including titanium dioxide $\left(\mathrm{TiO}_{2}\right)$, zinc oxide ( $\mathrm{ZnO})$, multiwall carbon nanotubes (MWCNT), and $\mathrm{CuO}$ NPs from aqueous environment [10]. Coagulation using commercially available polyaluminum chloride (PACl) was not effective in eliminating the NPs from the wastewater of industrial complex [11]. Moreover, the efficient removal of cadmium telluride (CdTe) quantum dots and many commercial NPs was achieved using a combination of alum coagulation as well as membrane filtration [12]. The particle size, surface properties, concentration of NPs, and organic ligands in an aqueous environment also affect the coagulation performance.

Studies reported that the coagulant type and concentration are the primary parameters controlling the coagulation-sedimentation (C/S) performance of metal oxide NPs, i.e., $\mathrm{C}_{60}$ and CNTs $[11,13]$. Iron-based coagulants such as ferric chloride (FC) in comparatively large amounts can remove the Aldrich humic acid (AHA)-coated CNTs [14]. A recent study investigated the removal of HA and surfactant-stabilized CNTs via the combination of alum and $\mathrm{PACl}$ coagulant. $\mathrm{PACl}$ showed better removal efficiency of CNTs than alum during the $\mathrm{C} / \mathrm{S}$ process [15]. Factors such as solution $\mathrm{pH}$ and ionic strength (IS) affect the colloidal behavior of NPs, as well as the activity of coagulants. IS neutralizes the negative surface potential and efficiently compresses the electrical double layer (EDL) around the particle and thus increases the aggregation of NPs in solution. Bian et al. reported that polydentate organic ligands such as AHA may enhance the dissolution of $\mathrm{ZnO}$ NPs at an alkaline (9-11) $\mathrm{pH}$ [16]. Moreover, process parameters such as stirring speed in the mixing and reacting phases may also influence the coagulation performance. However, studies exploring the coagulation behavior of organic ligand-stabilized $\mathrm{CuO}$ NPs under different hydraulic conditions and water matrices were rarely investigated by environmental scientists. Thus, it is necessary to comprehensively understand the $\mathrm{C} / \mathrm{S}$ behavior of organic ligand-stabilized $\mathrm{CuO}$ NPs in different hydraulic conditions and heterogenous water environments.

Therefore, the purpose of this study was to investigate the influence of process parameters and water chemistry on the elimination of organic ligand-stabilized $\mathrm{CuO}$ by PAFC. Tannic acid was used as a model hydrophilic organic ligand. Moreover, various parameters were altered to explore the effect of mixing speeds, $\mathrm{pH}$, and IS during the $\mathrm{C} / \mathrm{S}$ process.

\section{Results and Discussion}

\subsection{Characteristics of the Stabilized TA-CuO NP Suspension}

Figure 1A,B illustrates the different characteristics of prepared stock TA-CuO NP suspension in the three experimental groups. The addition of TA substantially decreased the surface potential of $\mathrm{CuO} \mathrm{NPs}$, thereby resulting in the formation of a TA-stabilized $\mathrm{CuO}$ NP suspension. The slight deviation can be observed in the characteristics of three stock TA-CuO NP suspensions, which might be related to the instability of probe sonication (Figure 1A,B). A significant difference in the initial concentration of CuO NPs (47.8 to $65.10 \mathrm{mg} \cdot \mathrm{L}^{-1}$ ) was noted. In contrast, the equilibrium concentration of TA and $\mathrm{pH}$ values remained stable in all three TA-CuO NP (cases 1, 2, and 3) suspensions. The $\zeta$-potential and HDD values of the three suspensions were $53.5 \pm 5.5 \mathrm{mg} \cdot \mathrm{L}^{-1},-48.8 \pm 3.7 \mathrm{mV}, 57.6 \pm 6.3$, and $210 \pm 5,235 \pm 8,180 \pm 1.5 \mathrm{~nm}$ respectively. Moreover, the result of initial experiments revealed that $80 \mathrm{~min}$ of sedimentation time was sufficient for the removal of destabilized $\mathrm{CuO}$ NPs to attain an equilibrium (Figure 1C). All three stock TA-CuO NPs solutions were semi-diluted with $\mathrm{pH}$ adjusted to 7.0 prior to use in different sets of experiments. 

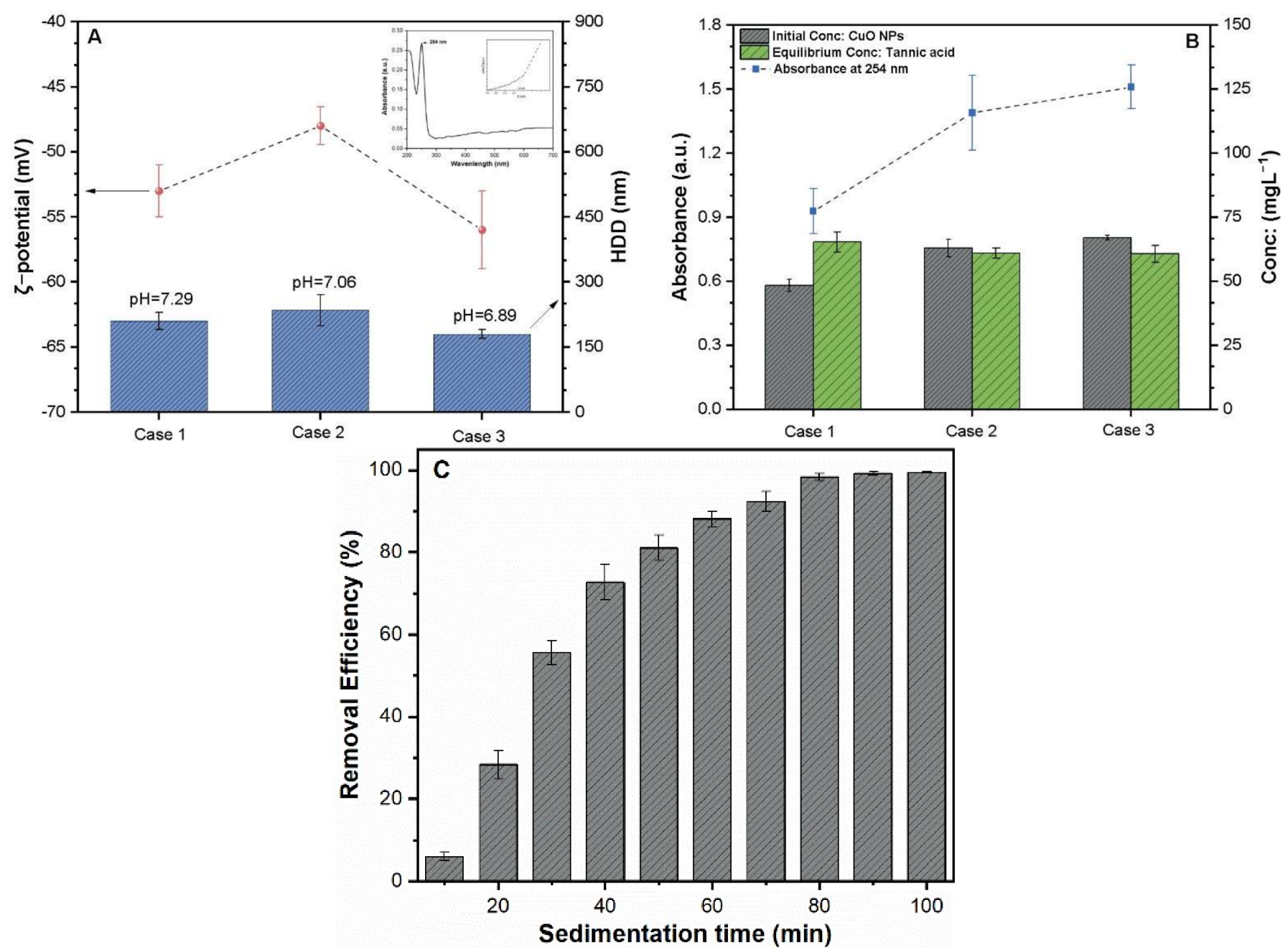

Figure 1. Characteristics of the TA-stabilized CuO NPs suspension. (A) $\zeta$-potential and HDD; (B) initial and equilibrium concentration of $\mathrm{CuO}$ and TA in different groups; $(\mathbf{C})$ influence of sedimentation time on the removal efficiency of TA-CuO NP suspensions.

\subsection{Effect of Hydraulic Settings on the Removal Efficiency of TA-CuO NPs}

Figure 2A illustrates the influence of stirring speed in the mixing phase on the removal of TA-CuO NP suspension. It was found that altering the stirring speed at the mixing phase had a marginal impact on the removal efficiency, and the removal curves mostly intersected at different points. The range of efficient coagulant concentrations (ECC) was $2.25-6.01 \mathrm{mg} \cdot \mathrm{L}^{-1}$, with the highest removal efficiency varying from $90-98 \%$. Furthermore, a slightly enhanced removal was observed ( $>98 \%)$ at a mixing speed of $680 \mathrm{rpm}$, which was set for the reacting phase experiments. Figure $2 \mathrm{~B}$ shows that the overall removal efficiency of TA-CuO NPs varied significantly with the change in the stirring speed; however, the ECC range remains unchanged $\left(2.25-6.01 \mathrm{mg} \cdot \mathrm{L}^{-1}\right)$. The enhanced removal of around $98 \%$ was achieved at the stirring speeds of 80 and $150 \mathrm{rpm}$, and then investigated at other stirring speeds (300, 490, and $680 \mathrm{rpm}$ ). Moreover, it is noteworthy that rapid mixing was not appropriate at $80 \mathrm{rpm}$. Thus, $150 \mathrm{rpm}$ was selected as the optimal stirring speed in the reacting phase for other sets of experiments.

In general, the effect of stirring speed in the reacting phase on the removal of TA-CuO NPs was found to be significant when compared with the mixing phase. The stirring speed of the mixing phase primarily affects the mixing intensity of the coagulant, thereby leading to the formation of $\mathrm{CuO} \mathrm{NP}$ colloids even at a low stirring speed. Altering the stirring speed during the mixing phase resulted in significant variation in the removal efficiencies, but the same speed in the reacting phase might affect the flocculation and the overall 
removal performance. At a low stirring speed, tiny $\mathrm{CuO}$ NP aggregates formed during the mixing phase were unable to collide with other NPs to produce large and dense flocs, while high stirring speeds generated high-strength shearing forces, which destroyed the flocs formed. The removal rate in both conditions was less than moderate. Our results are consistent with a previous study, which reported the increased removal of red dye at moderate stirring speed using iron salts and alum sulfate [17].
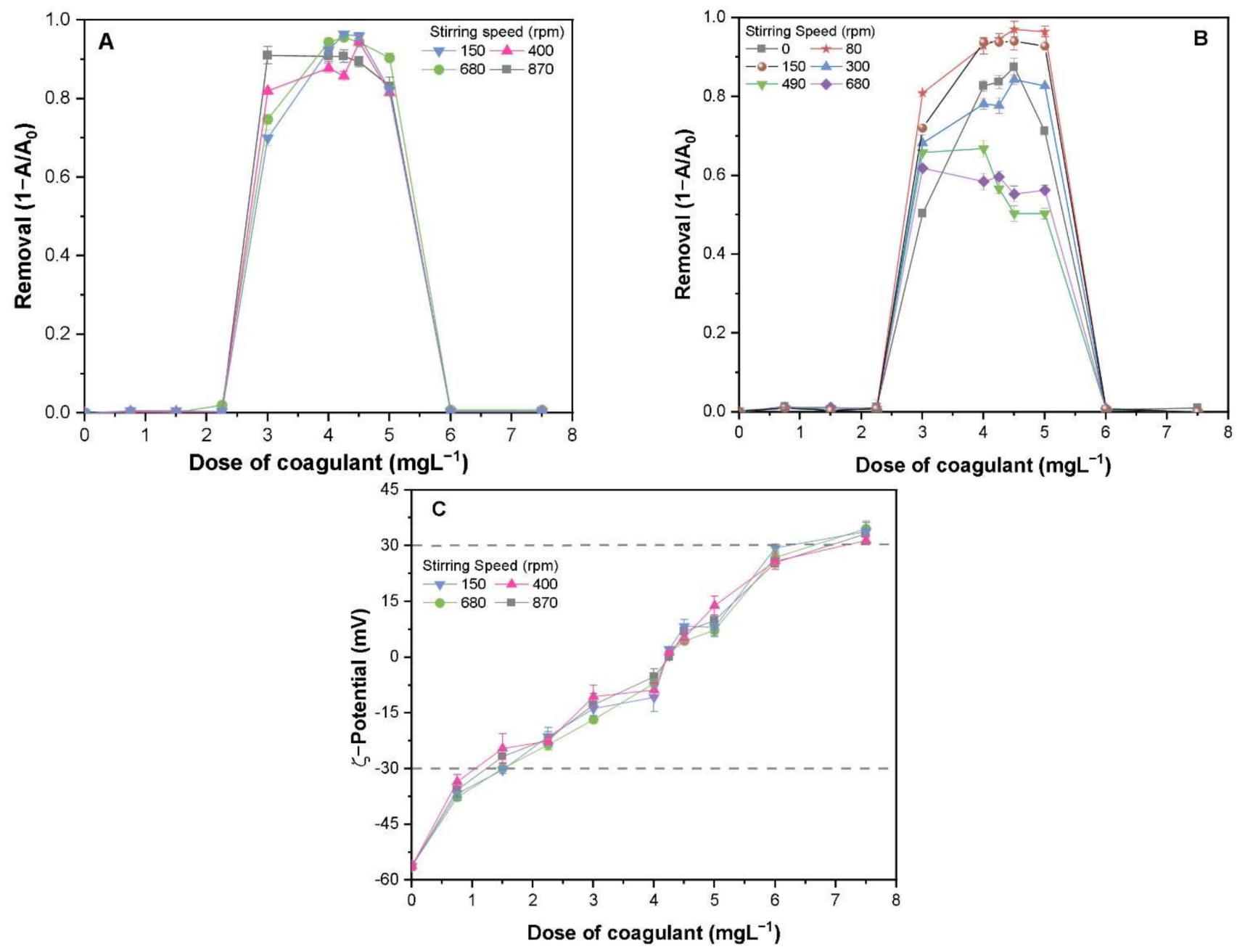

Figure 2. Removal efficiencies of TA-CuO NPs under various stirring speeds and PAFC dosages: (A) mixing phase, (B) reacting phase, and $(\mathbf{C}) \zeta$-potential of TA-CuO NPs.

To better understand the removal phenomenon, the $\zeta$-potential of TA-CuO NPs was determined under both process conditions. It was observed that the surface potential of TA-stabilized $\mathrm{CuO}$ NP suspension was steadily enhanced ( -56.05 to $38.7 \mathrm{mV}$ ) by raising PAFC concentration from $\left(0\right.$ to $\left.8 \mathrm{mg} \cdot \mathrm{L}^{-1}\right)$ as shown in Figure $2 \mathrm{C}$. The effect of change in the stirring speed in the mixing phase had insignificant influence on the surface charge of TA-CuO NPs, implying negligible interaction among the NPs and PAFC (Figure 2A,C). The $\zeta$-potential of TA-CuO NPs in the ECC range (ca. 2.25-6.01 mg. $\mathrm{L}^{-1}$ ) was between -30 and $30 \mathrm{mV}$. In this range, the maximum removal of TA-CuO NPs was achieved due to weak electrostatic repulsion forces among the collides, which was consistent with another study [16]. After optimal dosage, the higher PAFC concentration resulted in enhanced $\zeta$-potential above $30 \mathrm{mV}$, thereby decreasing the removal of TA-CuO NPs due to the strong electrostatic hindrance [18]. Consequently, the observed removal curves (Figure 2A,B) showed a distinct inverted " $U$ " shape. In general, higher and lower dosages of PAFC 
resulted in lower removal, suggesting the need for an optimum coagulant dose to ensure the effective coagulation of TA-stabilized NPs suspension.

\subsection{Influence of Solution $\mathrm{pH}$ on the Stability of TA-CuO NPS}

The colloidal stability of metal-based NPs in an aquatic environment largely depends upon the $\mathrm{pH}$ of the receiving body. As shown in Figure 3A, the addition of TA to $\mathrm{CuO}$ NPs reverses the $\zeta$-potential towards the negative trajectory. The TA-CuO NP suspension remained dispersed and stable at $\mathrm{pH}$ values of $5-11$, with an approximate HDD value of $280 \mathrm{~nm}$. Figure 3B shows that TA-CuO NPs rapidly sedimented between $\mathrm{pH} 3$ and 4 , with enhanced HDD. The increased rate of precipitation of the TA-CuO NPs under acidic $\mathrm{pH}$ conditions might be related to enhanced settling of colloids due to $\mathrm{H}$-bonding and/or polar interaction among the $\mathrm{CuO}$-adsorbed organic ligands without effective electrostatic repulsion. A recent study reported a similar $\mathrm{pH}$-dependent precipitation of multiwall carbon nanotubes in the presence of tannic acid [19]. Therefore, to minimize this effect in the experiment, the $\mathrm{pH}$ of the TA-CuO NP suspension was adjusted to between 5 and 10 .
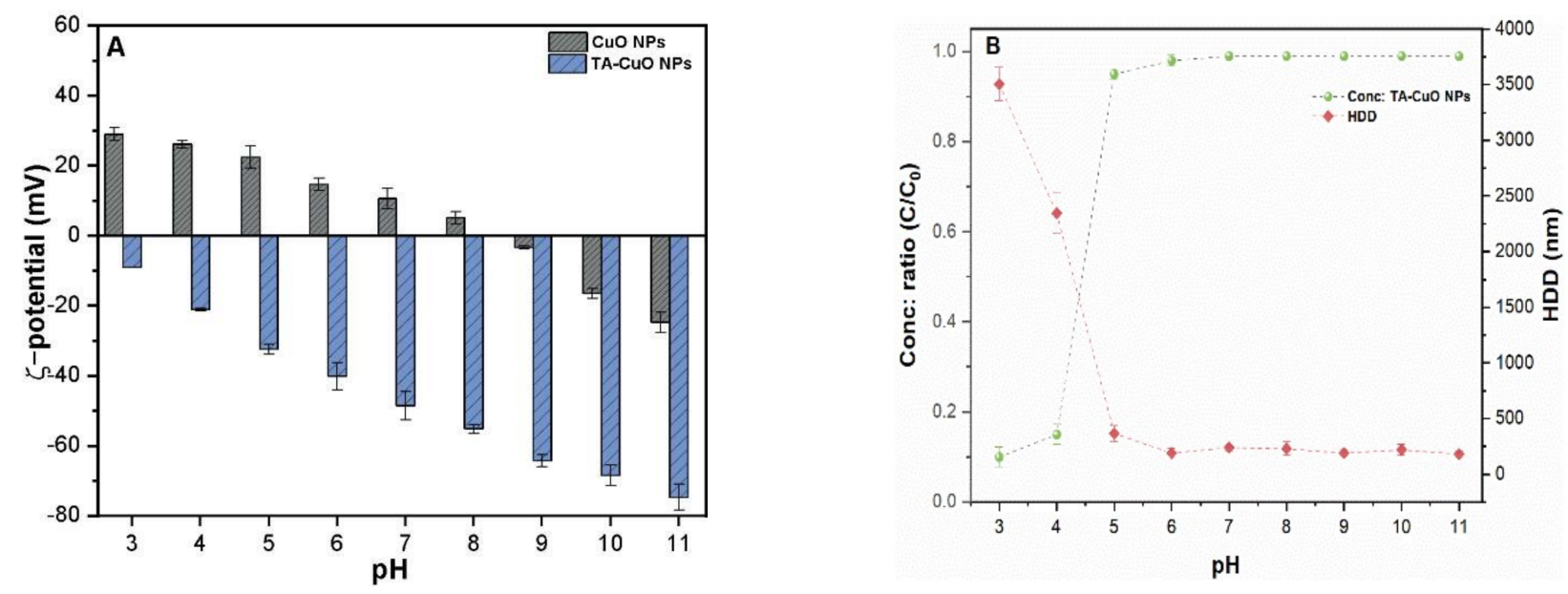

Figure 3. Under different solution pH levels: (A) $\zeta$-potential of $\mathrm{CuO}$ NPs with and without TA; (B) colloidal stability and HDD of the TA-CuO NPs. The concentration ratio $\mathrm{C} / \mathrm{C}_{0}$ indicates the colloidal stability of TA-CuO NP suspension.

\subsection{Influence of Solution $\mathrm{pH}$ on the Removal of TA-CuO NP Suspension}

The removal rate of TA-CuO NPs under different levels of solution $\mathrm{pH}$ is presented in Figure 4A. The coagulation curve continued to remain in an almost reverse " $\mathrm{U}$ " pattern at various $\mathrm{pH}$ conditions. However, a slight forward shift in the curve was observed with increasing suspension $\mathrm{pH}$ (Figure $4 \mathrm{~A}$ ). The removal efficiencies at various $\mathrm{pH}$ conditions remained the same; however, the effective PAFC dosage gradually increased from 2.25 to $5.75 \mathrm{mg} \cdot \mathrm{L}^{-1}$ at $\mathrm{pH} 5$ to $6.05-10.95 \mathrm{mg} \cdot \mathrm{L}^{-1}$ at initial $\mathrm{pH} 10$ (Figure $4 \mathrm{~A}$ ). These results suggest that the coagulation of TA-CuO NPs was feasible within the broad $\mathrm{pH}$ range and enhanced the removal performance with a lower coagulant dose at low $\mathrm{pH}$ values. The addition of PAFC coagulant lowered the solution $\mathrm{pH}$, especially at high initial $\mathrm{pH}$ conditions, due to the buffer effect of $\mathrm{Al}^{3+}$ and $\mathrm{Fe}^{3+}$ ions (Figure 4B). The decrease in $\mathrm{pH}$ value might lower the negative surface potential of TA-CuO NPs; however, it does not reverse the surface charge from negative to positive (Figure $3 \mathrm{~A}$ ). The high dosage of PAFC can oversaturate the negative TA-CuO NPs and positively charged colloids [20]. The $\zeta$-potential was increased with increasing PAFC concentration in the solution (Figure 4C). Moreover, the range of weak electrostatic repulsion $( \pm 30 \mathrm{mV})$ was enhanced with increasing suspension $\mathrm{pH}$. These results suggest the identical behavior of repulsive forces with the ECC range of individual suspension $\mathrm{pH}$ (Figure $4 \mathrm{~A})$. 

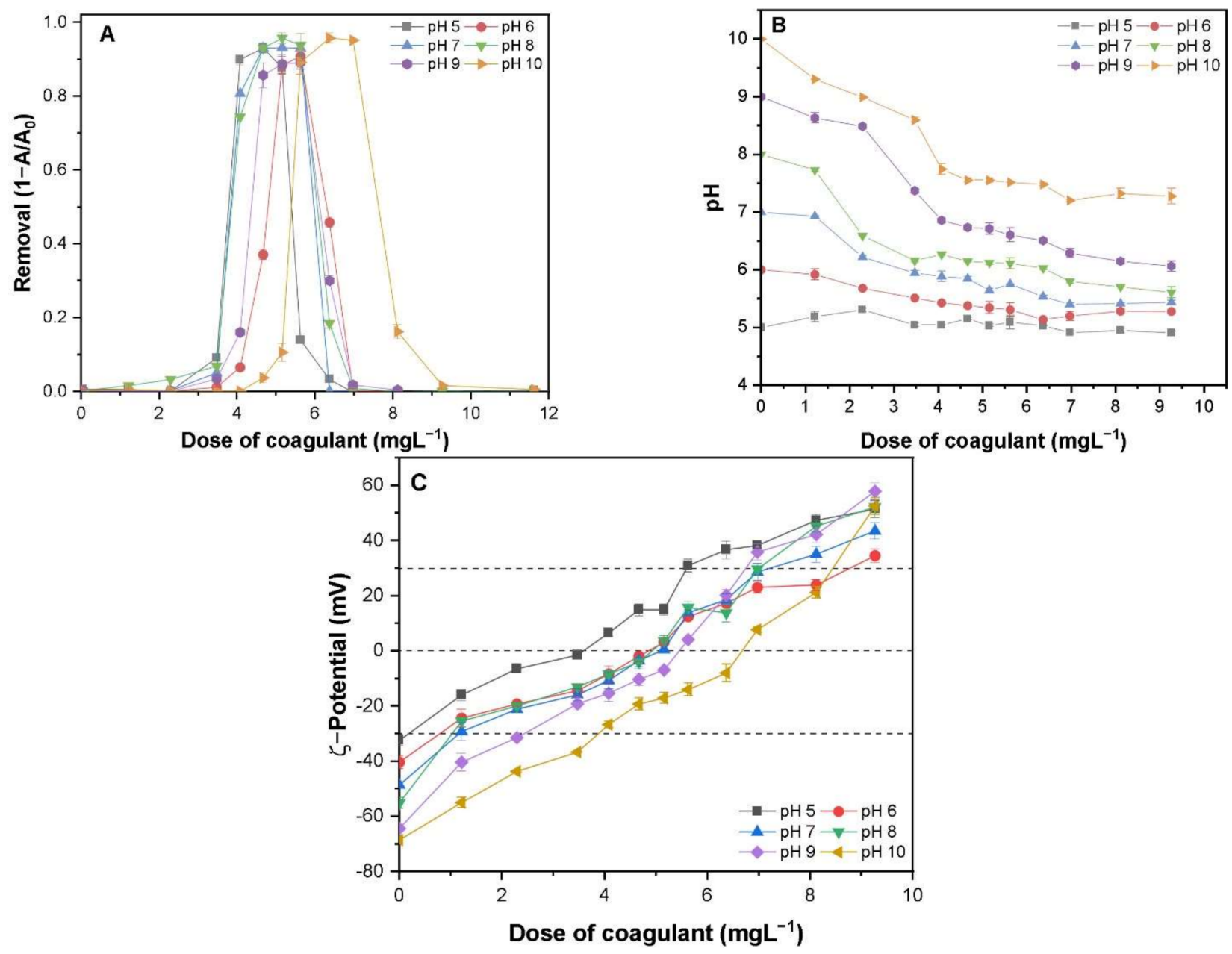

Figure 4. Effect of various PAFC dosages and solution $\mathrm{pH}$ on (A) removal efficiency; (B) final $\mathrm{pH}$ of suspension, and (C) $\zeta$-potential of TA-CuO NPs.

In addition, the suspension $\mathrm{pH}$ may control the coagulation behavior by altering the surface potential of NPs, product species of PAFC and their equilibrium hydrolysis [21]. The primary species of $\mathrm{Al}$ and $\mathrm{Fe}$ in PAFC solution include the monomer $\left(\mathrm{Al}_{\mathrm{a}}\right)$, polymer $\left(\mathrm{Al}_{\mathrm{b}}\right.$ or $\left.\mathrm{Al}_{13}\right)$, colloidal form $\left(\mathrm{Al}_{\mathrm{c}}\right)$, and $\mathrm{Fe}^{3+}$, respectively [21]. The concentration of polymer $\left(\mathrm{Al}_{\mathrm{b}}\right.$ or $\left.\mathrm{Al}_{13}\right)$ species was enhanced under the acidic/neutral environment and significantly decreased with increasing solution $\mathrm{pH}$ towards the alkaline zone. In contrast, the behavior of $\mathrm{Al}_{\mathrm{a}}$ species with suspension $\mathrm{pH}$ was opposite to that of polymer and colloidal form [22]. Moreover, $\mathrm{Fe}(\mathrm{III})$ at neutral $\mathrm{pH}$ facilitated the $\mathrm{C} / \mathrm{S}$ process as a substantial amount of $\mathrm{FeOOH}$ was produced. The positive charges of $\mathrm{Al}_{13}$ and $\mathrm{Fe}(\mathrm{III})$ species exhibit strong neutralizing as well as adsorbing capability, thereby removing the TA-CuO via coagulation [21]. The studied TA-CuO NPs suspension $\mathrm{pH}$ values range from 5.0 to 10 . However, an increase in the dosage of PAFC resulted in a decrease of final $\mathrm{pH}$ towards the acidic range (5.03-8.70) Figure 4B. The hydrolysis of PAFC may have influenced the coagulation behavior during the removal of organic ligand-stabilized CuO NPs. Moreover, the removal efficiency was similar under different $\mathrm{pH}$ values used.

\subsection{Influence of Electrolyte Concentration on the Stability and Removal of TA-CuO NPs}

The addition of monovalent electrolyte $\mathrm{KCl}$ greatly decreased the negative charge potential of TA-CuO NPs, thereby destabilizing colloidal suspension (Figure 5A). Destabilized TA-CuO NPs exhibited a standard precipitation curve against the IS of $\mathrm{KCl}$. The critical coagulation concentration (CCC) of $\mathrm{KCl}$ for TA-CuO NPs was calculated using Derjaguin-Landau-Verwey-Overbeek (DLVO) theory [23]. The CCC can be defined as 
the minimum amount of an electrolyte required to destabilize NP suspension completely. The value of CCC provides essential information about NPs stability and can thus be used to predict the fate and transport of NPs in natural waters. The CCC of $\mathrm{KCl}$ was found to be $0.225 \mathrm{mM}$, where more than $50 \%$ of the suspended $\mathrm{CuO}$ NPs destabilize. Figure $5 \mathrm{~B}$ illustrates the removal curves of TA-CuO NP suspension under different IS. It can be observed that the incorporation of $\mathrm{KCl}$ changes the maximum removal efficiency and ECC range of PAFC. The removal efficiency remained constant at concentrations below the $\mathrm{CCC}$ of $\mathrm{KCl}$; however, it was substantially decreased when the concentration was above CCC. The enhanced IS significantly increased the effective PAFC concentration range and lowered the required PAFC dosage to achieve the highest removal efficiency (Figure 5B). Thus, a lower concentration of monovalent salt ions improved the coagulation performance. In contrast, the high IS may hinder the ionic activity of the charged species of $\left.\mathrm{Al} / \mathrm{Fe}\left(\mathrm{AlO}_{4} \mathrm{Al}_{12}(\mathrm{OH})_{24}\left(\mathrm{H}_{2} \mathrm{O}\right)_{12}\right)^{7+}, \mathrm{Fe}(\mathrm{OH})_{2}\right)$, thus decreasing the removal efficiency. A lower removal rate of hydrophobic organic ligand at high IS was reported in a previous study [22]. At optimum concentration, the electrolyte efficiently compresses the EDL around the TA-CuO NPs and reduces the absolute surface charge $(-30 \mathrm{mV}$ to $+30 \mathrm{mV})$ of TA-CuO NP suspension under different concentrations of PAFC (Figure 5). Moreover, the range of coagulant concentrations was enhanced with increased IS of solution and showed a similar ECC range of individual IS (Figure 5B,C). The increased removal in these conditions might be attributed to the weak electrostatic hindrance effect, enhancing the forces of attraction among NPs.
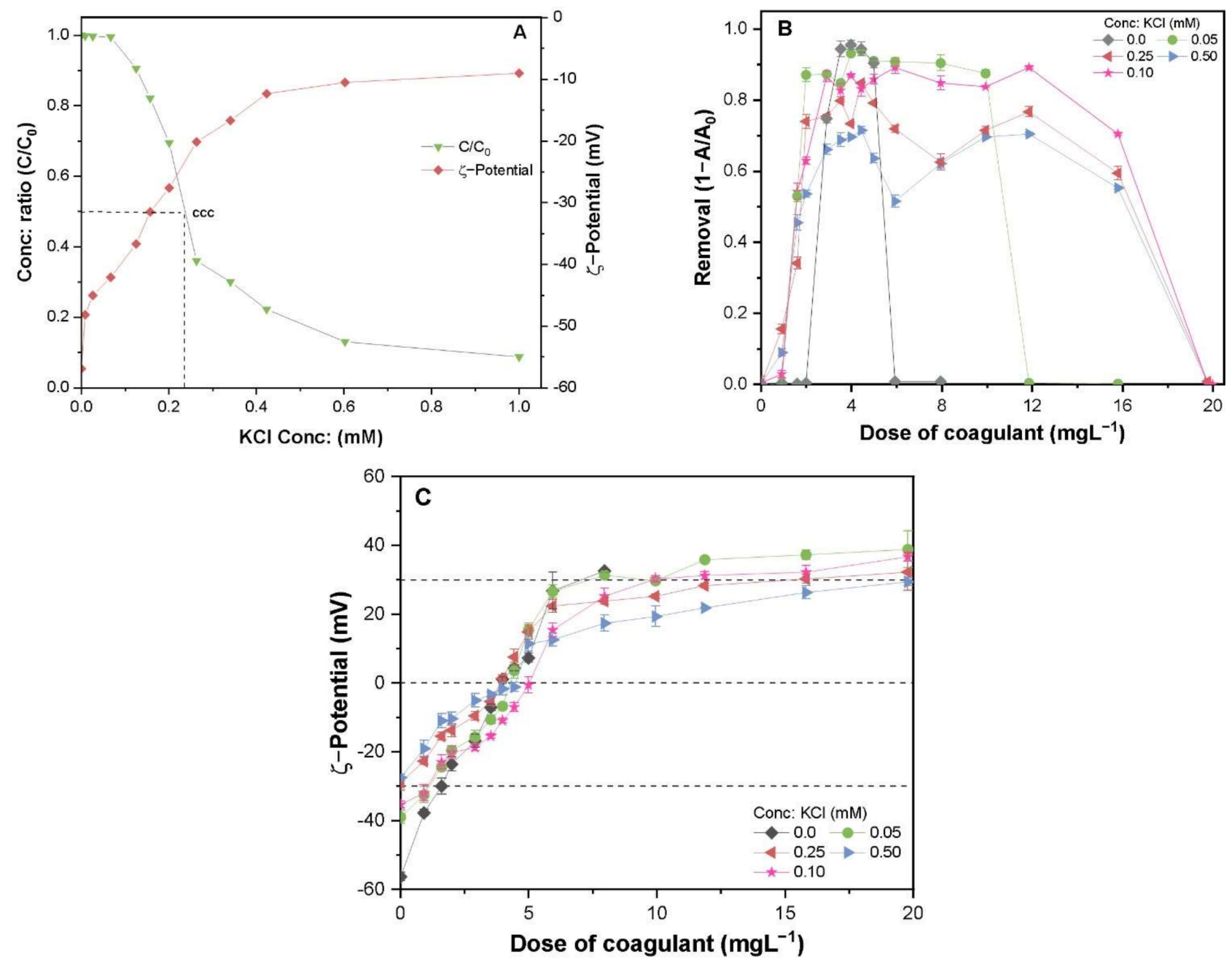

Figure 5. Effect of various $\mathrm{KCl}$ concentrations on TA-CuO NPs $(\mathbf{A})$ stability $\left(\mathrm{C} / \mathrm{C}_{0}\right)$; $(\mathbf{B})$ removal efficiency by PAFC, and (C) corresponding $\zeta$-potential at various dosages of PAFC. 


\subsection{Effect of TA-Stabilized $\mathrm{CuO}$ NP Concentration on the Removal Process}

Figure 6A illustrates the removal patterns of the three sets of diluted stock suspension of TA-CuO NPs obtained in previous experiments. It is noteworthy that the pattern of curves and removal efficiency remains constant, whereas the ECC range shifted forward with an enhanced concentration of TA-stabilized $\mathrm{CuO}$ NPs suspension. A higher dose of coagulant was required to achieve a similar removal efficiency for the TA-CuO NP suspension containing a higher concentration of $\mathrm{CuO}$ NPs. For instance, in case 1 , the required PAFC dosage was about $3.12 \mathrm{mg} \cdot \mathrm{L}^{-1}$ to achieve $78 \%$ removal of TA-stabilized $\mathrm{CuO}$ NPs containing $23.9 \mathrm{mg} \mathrm{CuO}$ NPs. However, the added concentration of PAFC was $4.07 \mathrm{mg} \cdot \mathrm{L}^{-1}$ to achieve a similar removal efficiency of ligand-stabilized $\mathrm{CuO} \mathrm{NPs}$ at 30.1-31.6 mg CuO NPs/L. The coagulation curves of TA suspension $\left(40 \mathrm{mg} \cdot \mathrm{L}^{-1}\right)$ at neutral $\mathrm{pH}$ also showed the same inverted " $\mathrm{U}$ " pattern (Figure 6A). The removal efficiency and ECC range of TA suspension were higher compared with TA-CuO NP solutions. These findings strongly suggest the interaction between PAFC and ligand molecules via $\mathrm{H}$-bonding and other associated groups present in TA.
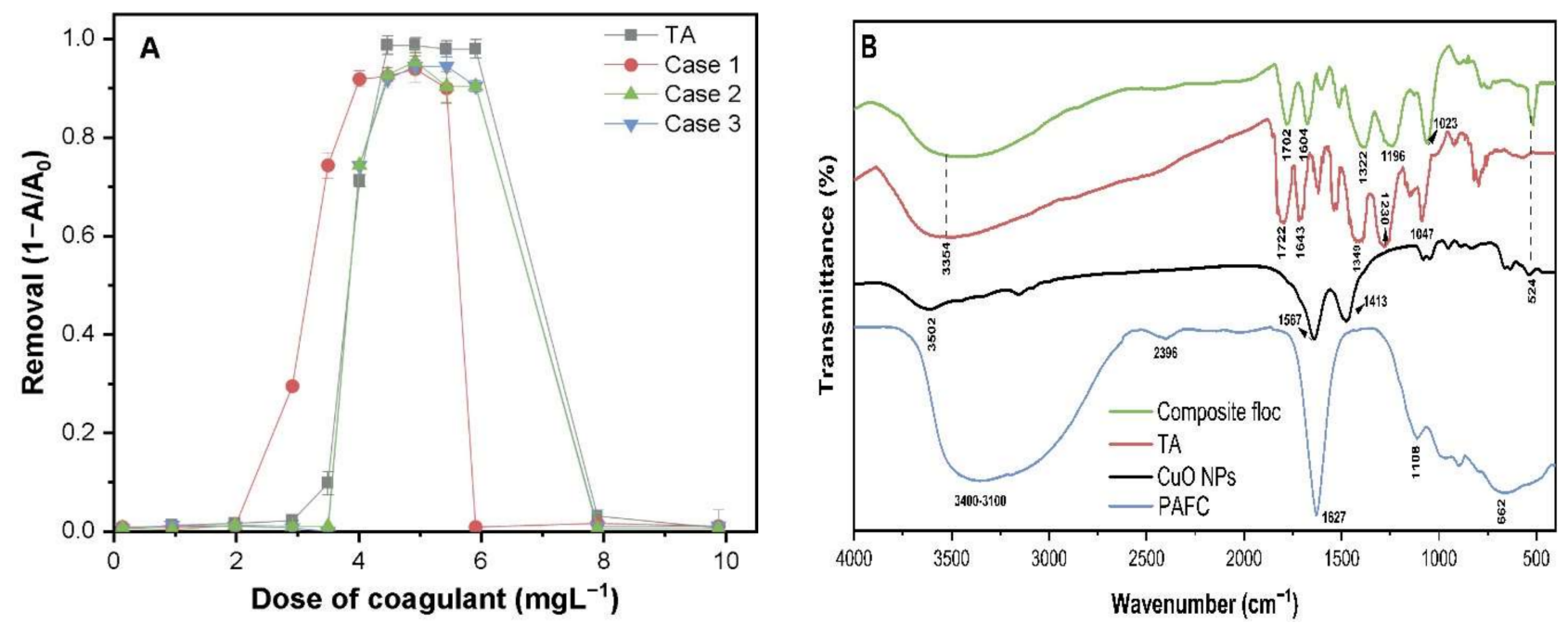

Figure 6. (A) Removal efficiencies of 3 sets of TA-CuO NP suspensions and the dissolved TA by PAFC; (B) FTIR spectra of pristine chemicals, i.e., CuO-NPs, PAFC, TA and composite floc obtained at optimum dose.

The FTIR spectra of pristine chemicals including $\mathrm{CuO}, \mathrm{TA}, \mathrm{PAFC}$, and composite flocs obtained after the C/S process were analyzed to elucidate the probable removal mechanism, as illustrated in Figure 6B. The broad spectrum peaks around $3500-3100 \mathrm{~cm}^{-1}$ were attributed to $\mathrm{OH}$ stretching and $(\mathrm{Al} / \mathrm{Fe}-\mathrm{OH})$ vibration frequency [23]. The peaks observed around $1722,1643,1230$, and $1047 \mathrm{~cm}^{-1}$ were associated with stretching vibrations of $\mathrm{C}=\mathrm{O}$, aromatic $\mathrm{C}=\mathrm{C}$, phenolic $\mathrm{C}-\mathrm{O}$, and $\mathrm{C}-\mathrm{O}(\mathrm{H})$, respectively. In contrast, the peaks at 662 and $524 \mathrm{~cm}^{-1}$ were ascribed to the bending vibration of $\mathrm{Fe}-\mathrm{OH}-\mathrm{Fe}$ and $\mathrm{Cu}-\mathrm{O}$ vibration frequency, respectively. Organic ligands such as TA contain many $\mathrm{OH}$ functional groups in their steric structure, which prevent the interaction between moieties with the surface of $\mathrm{CuONPs}$ and others act as functional groups.

The IR spectra of composite floc (TA-CuO + PAFC) obtained after coagulation show a significant shift in major groups such as $\mathrm{C}=\mathrm{O}, \mathrm{C}-\mathrm{O}$ and $\mathrm{C}=\mathrm{C}$ along with minor variations in the associated groups (Figure $6 \mathrm{~B}$ ). For example, the $\mathrm{C}=\mathrm{O}$ stretching band around $1722 \mathrm{~cm}^{-1}$ was decreased and shifted to lower wavenumbers at around $1702 \mathrm{~cm}^{-1}$, thereby confirming the strong inner-sphere complexation with free metal ions. Furthermore, a significant shift occurred in the $\mathrm{C}-\mathrm{O}\left(1349 \mathrm{~cm}^{-1}\right.$ to $\left.1322 \mathrm{~cm}^{-1}\right)$ bond stretching vibration with decreased intensity, suggesting the interaction between $\mathrm{Fe}^{3+}$ and the phenolic hydroxyl group of TA during coagulation [24]. Few spectral peaks in composite floc around 1600 to $1000 \mathrm{~cm}^{-1}$ were attributed to the complexation of ligand molecules and $\mathrm{Al} / \mathrm{Fe}$ ions. These findings are consistent with the study of Zhao and Liu, which reported that $\mathrm{OH}$ groups in TA 
facilitate the formation of metal complexes [25]. Moreover, the Fe ions may form complexes with $(-\mathrm{C}-\mathrm{O})$ via two adjacent hydroxyls (catechols), while the co-existence of a third adjacent hydroxyl (pyrogallols) enhanced the stability of the formed complex [26]. The major changes and increased strength of certain bands in composite flocs facilitated the complex reaction between metal ions and PAFC in ligand-containing waters. Thus, based on the FT-IR spectrum, the potential removal mechanism of TA-CuO NPs might involve a combination of charge neutralization, inner-sphere complexation, and adsorption.

\section{Materials and Methods}

\subsection{Materials}

The selected CuO NPs (Sigma Aldrich, St. Louis, MO, USA) with supplier-reported characteristics (purity $>99.0 \%$, mean outer diameter $<50 \pm 6 \mathrm{~nm}$ ) were used without further purification. The coagulant polyaluminum ferric chloride (PAFC) containing $26 \%$ of $\mathrm{Al} / \mathrm{Fe}$ was purchased from water treatment material company Gongyi Tenglong Co., Ltd., Qingdao, China. Tannic acid (Sigma Aldrich, USA) was preferred to reflect the relatively hydrophilic organic ligands with a molecular weight of about $1700 \mathrm{Da}(4)$.

\subsection{Stock Solution}

TA stock suspension was prepared by weighing $100 \mathrm{mg}$ of TA powder and dissolved in $100 \mathrm{~mL}$ of ultrapure Milli-Q water. The suspension $\mathrm{pH}$ was adjusted to neutral with $100 \mathrm{mM} \mathrm{HCl}$ to completely dissolve the organic ligand. The CuO NPs $\left(200 \mathrm{mg} \cdot \mathrm{L}^{-1}\right)$ were probe-sonicated $(40 \mathrm{kHz}, 400 \mathrm{~W}, 30 \mathrm{~min})$ in $\mathrm{TA}\left(50 \mathrm{mg} \cdot \mathrm{L}^{-1}\right)$ suspension. Subsequently, the obtained ligand-stabilized $\mathrm{CuO} N \mathrm{NP}$ suspension was further centrifuged at $3200 \mathrm{rpm}$ for $40 \mathrm{~min}$ and then stored in the dark. Prior to the experiment, the concentration of dissolved TA in stabilized $\mathrm{CuO}$ NPs suspension was analyzed with total organic carbon (TOC) analyzer (TOC-VCPH, Shimadzu, Japan). Moreover, the concentration of CuO NPs was also calibrated by measuring the absorbance at $254 \mathrm{~nm}$. The stock solution $50 \mathrm{mg} \cdot \mathrm{L}^{-1}$ of commercially available PAFC coagulant ( $26 \% \mathrm{Al}$ content) was prepared by directly dissolving into the ultrapure Milli-Q water.

\subsection{Coagulation Experiments}

The coagulation-sedimentation-flocculation experiments were performed in a jar test apparatus with six automatic lifting mixers (Model: SJ-10, Young Hana Tech Co., Ltd., Gyeongsangbuk-Do, Korea). The ligand-stabilized $\mathrm{CuO}$ NP suspension was diluted to the desired concentration prior to the jar test experiments. In addition, $\mathrm{pH}$ was adjusted to pre-determined level before coagulation experiments. In short, at the beginning of rapid mixing (mixing phase), $5 \mathrm{~mL}$ of PAFC and $45 \mathrm{~mL}$ of TA-stabilized $\mathrm{CuO}$ NP suspension were transferred to $100 \mathrm{~mL}$ glass beakers. The rapid mixing was sustained for $1 \mathrm{~min}$ and the suspension was then slowly mixed (reacting stage) for $20 \mathrm{~min}$. The mixture was left to sediment for $100 \mathrm{~min}$, followed by the analysis of the collected supernatants to determine the final solution $\mathrm{pH}$ and turbidity at $254 \mathrm{~nm}$ (UV-vis absorbance).

\subsection{Experimental Matrices}

Following the above procedure, three sets of experiments were designed to investigate the influence of various parameters, i.e., hydraulic condition, solution $\mathrm{pH}$, and IS. In the first set of trials, the effects of hydraulic setting on the removal efficiency were analyzed at different stirring speeds in the mixing and reacting phases. The stirring speed in the reacting phase was set at $150 \mathrm{rpm}$ to investigate the effect of the stirring speed during the mixing phase. Next, the effect of the stirring speed on the reacting phase was determined and the stirring speed in the mixing phase was set at $680 \mathrm{rpm}$. Subsequently, the mixing phase, the surface charge and the hydrodynamic diameter (HDD) of the NPs were examined. In the remaining two sets of $\mathrm{C} / \mathrm{S}$ experiments, the influence of different solution $\mathrm{pH}$ (5-11) and IS values $(0-1.0 \mathrm{mM})$ of TA-CuO suspension were investigated. The $\mathrm{pH}$ and IS of the solution were adjusted using $\mathrm{NaOH}, \mathrm{HCl}$, and $\mathrm{KCl}$, respectively. In both sets of trials, the 
stirring speeds in the rapid mixing and reacting phases were set up at 680 and $150 \mathrm{rpm}$, respectively. Moreover, under similar experimental conditions in the absence of $\mathrm{CuO}$ NPs, the removal efficiency of TA solution $\left(40 \mathrm{mg} \cdot \mathrm{L}^{-1}\right)$ by PAFC was determined. The removal efficiency of $\mathrm{CuO}$ NPs was calculated by measuring the absorbance at $254 \mathrm{~nm}$ before and after the coagulation experiment.

\subsection{Analytical Procedure}

The residual concentration of $\mathrm{CuO}$ NPs was determined by measuring the absorbance at $254 \mathrm{~nm}$ with a UV-Vis spectrophotometer (Optizen, 2120 UV-Vis, Mecasys, Korea). A zetasizer (Nano-ZS90, Malvern, UK) was used to measure the Zeta potential and the HDD of NPs. In addition, to elucidate potential removal mechanisms, Fourier transform infrared analysis (FT/IR-4700, JASCO Analytical Instruments, Easton, PA, USA) in the range of 400 to $4000 \mathrm{~cm}^{-1}$ was conducted before and after the $\mathrm{C} / \mathrm{S}$ experiments. Each experiment was repeated three times and the relative standard deviations (STD) were recorded as $<5 \%$.

\section{Conclusions}

In the present work, we explored the effect of hydraulic settings and water chemistry on the removal of TA-stabilized $\mathrm{CuO}$ NPs via PAFC coagulation. The stirring speed in the reacting phase affects the development and shape of precipitated floc by altering the shear forces, thus affecting the overall efficiency. Lower $\mathrm{pH}$ and high IS conditions may facilitate the destabilization and decrease of TA-CuO NPs and thereby improve the removal efficiency. In contrast, high IS (above CCC) minimizes the removal efficiency due to inhibition of the activity of PAFC hydrolysate. The discrepancy in the initial mass of TA-CuO NPs observed affects the required coagulant dose and removal rate of NPs.

The FT-IR study of composite flocs indicated the role of primary mechanisms, i.e., charge neutralization, complexation, and adsorption, in the removal of TA-CuO NPs via coagulation. Overall, the results provide insight into the removal behavior of ligandstabilized $\mathrm{CuO}$ NPs from heterogeneous water environments via the coagulation process.

Author Contributions: Conceptualization, R.K.; methodology, R.K. and K.H.L.; software, R.K.; validation, R.K, M.A.I. and K.H.L.; formal analysis, R.K. and K.H.L.; investigation, R.K.; resources, R.K. and K.H.L.; data curation, R.K.; writing-original draft preparation, R.K.; writing-review and editing, R.K., M.A.I. and K.H.L.; visualization, R.K. and M.A.I.; supervision, R.K.; project administration, R.K. and K.H.L. All authors have read and agreed to the published version of the manuscript.

Funding: This work was supported by the Korea Environment Industry and Technology Institute (KEITI) through the Environmental R\&D Project on the Disaster Prevention of Environmental Facilities Project, funded by the Korea Ministry of Environment (MOE) (2020002870004).

Data Availability Statement: The data presented in this study are available on request from the corresponding author.

Acknowledgments: This study was jointly conducted by the Department of Chemical Engineering, Quaid-e-Awam University of Engineering, Science and Technology (QUEST), Nawabshah, Pakistan, and Department of Civil and Environmental Engineering, Hanyang University, Seoul, Korea.

Conflicts of Interest: The authors declare no conflict of interest.

Sample Availability: Not available.

\section{References}

1. Sun, T.Y.; Bornhöft, N.A.; Hungerbühler, K.; Nowack, B. Dynamic probabilistic modeling of environmental emissions of engineered nanomaterials. Environ. Sci. Technol. 2016, 50, 4701-4711. [CrossRef] [PubMed]

2. Pietroiusti, A.; Stockmann-Juvala, H.; Lucaroni, F.; Savolainen, K. Nanomaterial exposure, toxicity, and impact on human health. WIREs Nanomed. Nanobiotechnol. 2018, 10, e1513. [CrossRef]

3. Zhao, J.; Lin, M.; Wang, Z.; Cao, X.; Xing, B. Engineered nanomaterials in the environment: Are they safe? Crit. Rev. Environ. Sci. Technol. 2021, 51, 1443-1478. [CrossRef] 
4. Peng, C.; Shen, C.; Zheng, S.; Yang, W.; Hu, H.; Liu, J.; Shi, J. Transformation of CuO Nanoparticles in the Aquatic Environment: Influence of $\mathrm{pH}$, Electrolytes and Natural Organic Matter. Nanomaterials 2017, 7, 326. [CrossRef]

5. Xiao, Y.; Vijver, M.G.; Peijnenburg, W.J.G.M. Impact of water chemistry on the behavior and fate of copper nanoparticles. Environ. Pollut. 2018, 234, 684-691. [CrossRef] [PubMed]

6. Bondarenko, O.; Juganson, K.; Ivask, A.; Kasemets, K.; Mortimer, M.; Kahru, A. Toxicity of Ag, CuO and ZnO nanoparticles to selected environmentally relevant test organisms and mammalian cells in vitro: A critical review. Arch. Toxicol. 2013, 87, 1181-1200. [CrossRef]

7. Kiser, M.A.; Ryu, H.; Jang, H.; Hristovski, K.; Westerhoff, P. Biosorption of nanoparticles to heterotrophic wastewater biomass. Water Res. 2010, 44, 4105-4114. [CrossRef]

8. Westerhoff, P.K.; Kiser, A.; Hristovski, K. Nanomaterial removal and transformation during biological wastewater treatment. Environ. Mar. 2013, 30, 109-117. [CrossRef]

9. Springer, F.; Laborie, S.; Guigui, C. Removal of $\mathrm{SiO} 2$ nanoparticles from industry wastewaters and subsurface waters by ultrafiltration: Investigation of process efficiency, deposit properties and fouling mechanism. Sep. Purif. Technol. 2013, 108, 6-14. [CrossRef]

10. Abbott Chalew, T.E.; Ajmani, G.S.; Huang, H.; Schwab, K.J. Evaluating nanoparticle breakthrough during drinking water treatment. Environ. Health Perspect. 2013, 121, 1161-1166. [CrossRef] [PubMed]

11. Chang, M.R.; Lee, D.J.; Lai, J.Y. Nanoparticles in wastewater from a science-based industrial park-Coagulation using polyaluminum chloride. J. Environ. Manag. 2007, 85, 1009-1014. [CrossRef] [PubMed]

12. Zhang, Y.; Chen, Y.; Westerhoff, P.; Crittenden, J.C. Stability and removal of water soluble CdTe quantum dots in water. Environ. Sci. Technol. 2007, 42, 321-325. [CrossRef]

13. Petosa, A.R.; Jaisi, D.P.; Quevedo, I.R.; Elimelech, M.; Tufenkji, N. Aggregation and deposition of engineered nanomaterials in aquatic environments: Role of physicochemical interactions. Environ. Sci. Technol. 2010, 44, 6532-6549. [CrossRef]

14. Boncel, S.; Kyziol-Komosińska, J.; Krzyzewska, I.; Czupiol, J. Interactions of carbon nanotubes with aqueous/aquatic media containing organic/inorganic contaminants and selected organisms of aquatic ecosystems-A review. Chemosphere 2015, 136, 211-221. [CrossRef]

15. Liu, N.; Liu, C.; Zhang, J.; Lin, D. Removal of dispersant-stabilized carbon nanotubes by regular coagulants. J. Environ. Sci. 2012, 24, 1364-1370. [CrossRef]

16. Bian, S.W.; Mudunkotuwa, I.A.; Rupasinghe, T.; Grassian, V.H. Aggregation and dissolution of $4 \mathrm{~nm} \mathrm{ZnO}$ nanoparticles in aqueous environments: Influence of $\mathrm{pH}$, ionic strength, size, and adsorption of humic acid. Langmuir 2011, 27, 6059-6068. [CrossRef]

17. Merzouk, B.; Gourich, B.; Madani, K.; Vial, C.; Sekki, A. Removal of a disperse red dye from synthetic wastewater by chemical coagulation and continuous electrocoagulation. A comparative study. Desalination 2011, 272, 246-253. [CrossRef]

18. Wang, Y.; Xue, N.; Chu, Y.; Sun, Y.; Yan, H.; Han, Q. CuO nanoparticle-humic acid (CuONP-HA) composite contaminant removal by coagulation/ultrafiltration process: The application of sodium alginate as coagulant aid. Desalination 2015, 367, $265-271$. [CrossRef]

19. Lin, D.; Liu, N.; Yang, K.; Xing, B.; Wu, F. Different stabilities of multiwalled carbon nanotubes in fresh surface water samples. Environ. Pollut. 2010, 158, 1270-1274. [CrossRef]

20. Surawanvijit, S.; Liu, H.H.; Kim, M.; Cohen, Y. Removal of Metal Oxide Nanoparticles from Aqueous Suspensions. Sep. Sci. Technol. 2014, 49, 161-170. [CrossRef]

21. Tang, H.; Xiao, F.; Wang, D. Speciation, stability, and coagulation mechanisms of hydroxyl aluminum clusters formed by PACl and alum: A critical review. Adv. Colloid Interface Sci. 2015, 226, 78-85. [CrossRef] [PubMed]

22. Wang, Y.; Gao, B.Y.; Xu, X.M.; Xu, W.Y. The effect of total hardness and ionic strength on the coagulation performance and kinetics of aluminum salts to remove humic acid. Chem. Eng. J. 2010, 160, 150-156. [CrossRef]

23. Păcală, A.; Vlaicu, I.; Radovan, C. Comparative studies on the efficiency of aluminium coagulants. Environ. Eng. Manag. J. 2012, 11, 427-434. [CrossRef]

24. Rajar, K.; Soomro, R.A.; Ibupoto, Z.H.; Balouch, S.; Balouch, A. Tannic acid assisted copper oxide nanoglobules for sensitive electrochemical detection of bisphenol A. Int. J. Food Prop. 2017, 20, 1359-1367. [CrossRef]

25. Zhao, J.; Liu, Y.; Pan, B.; Gao, G.; Liu, Y.; Liu, S.; Liang, N.; Zhou, D.; Vijver, M.G.; Peijnenburg, W.J.G.M. Tannic acid promotes ion release of copper oxide nanoparticles: Impacts from solution $\mathrm{pH}$ change and complexation reactions. Water Res. 2017, 127, 59-67. [CrossRef]

26. Zhang, Y.; Li, S.; Wang, X.; Ma, X.; Wang, W.; Li, X. Synthesis, purification and characterization of polyaluminum ferric chloride (PAFC) with high $(\mathrm{Al}+\mathrm{Fe}) \mathrm{b}$ content. Sep. Purif. Technol. 2015, 146, 311-316. [CrossRef] 